\title{
Rethinking the selection of learning technologies
}

\author{
John G Hedberg \\ University of New South Wales
}

\begin{abstract}
In this paper, the criteria for selecting modern learning technologies are discussed and it is suggested that four teaching/learning activities might form the basis for selection combined with a number of types of conceptual representations. The most important aspects for a designer are the match between learning task and its ability to be presented or manipulated by the learner using a decreasing range of information technologies.
\end{abstract}

Fifteenth century Europeans 'knew', that the sky was made of closed concentric crystal spheres, rotating around a central earth and carrying the stars and planets. That 'knowledge' structured everything they did and thought, because it told them the truth. Then Galileo's telescope changed the truth. (Burke, 1986, p.9)

Over the past three years we have seen major changes in the information technologies. With the advent of the most recent computers such as the NeXT workstation, we are presented with a black box which enables words, numbers, visuals, sounds, dictionaries, thesauri, and external events to be controlled, manipulated and represented to the user in a variety of forms, often simultaneously, and also to other users linked into a network. Over this period, significant developments have also occurred in conceptualising research into the use of media in education and training. It is this relationship which forms the basis of this paper; the discussion will be divided into three main elements - technology, instructional design, and some ways of bridging the cultures and selecting modern media. 
We live in a world where ideas and manipulations can be achieved simply with tools such as computers and computer-controlled robots, the challenge for instructional designers is to recognise the possibilities and employ technologies through which the learner can manipulate the ideas, concepts and even physical skills being taught. In the past where media have been selected for learning, the algorithms often focussed upon the simple identification of attributes, motion versus still, colour versus black and white, projected versus opaque, etc (see for example, Kemp, 1977 \& Romiszowski, 1981). With the sophistication of todays learning technologies, these rather simple conceptions are no longer adequate. The choices are most often within one medium rather than between a variety of media forms. The classification schemes are difficult to use when you are looking at combinations of forms within the one lesson presentation. To achieve better use of information technologies the instructional designer needs more than a simplistic grasp of the possibilities of the technology.

\section{Looking at technologies}

Technologies of many types have been available to the designer since the first blackboard was used to demonstrate a concept visually in ways that were not possible with speech alone. Over the years teachers were provided with resources and hardware that enabled greater experiences to be included in the instructional process. With individual presentation technologies becoming more accessible on a mass basis, individual students have access to these tools in the classroom and at home.

The movement towards more integration of systems and technologies has provided an interesting environment for designers. It is becoming less necessary to learn about the diversity of different hardware systems as they start to adopt common user-interfaces and employ one or two formats for delivery. By way of a simple example, the new disk drives available with the latest Macintosh computers can read and write Apple II, Macintosh and IBM, high- and low-density formats - one drive suits all! Thus conceptualising anything in narrow hardware terms will not address the concepts to be learned and cognitive requirements of the task.

\section{Technology as hardware}

The use of the term technology has been often confused in the literature. Historically educational technology was technology equated with technology-as-hardware. This has referred to the audiovisual media or the communications technologies of print, audio, video and film. In the classroom, this has been 'showing a videotape' on a videotape recorder or 'playing an audiotape' on a audiocassette recorder. Many designers still view the term educational technology in this machine-based context. 
This approach has always been limited by the availability of the necessary equipment, but such a limited conception of technology should not be the driving force for developing instructional programs for the next decade. The cost of hardware is decreasing, and the number of elements required to form a useful workstation is also declining.

The workstation concept, which has grown with the advent of the word processor and the microcomputer, on which most are based, has enabled the presentation and manipulation of concepts in ways previously only possible with combination of media forms or more sophisticated computer systems. This power of manipulation and presentation of ideas has not gone unnoticed by such proponents for the use of technology in the teaching of mathematical ideas (Kaput, 1986; Papert, 1980; Pea, 1987). Foremost among these enthusiasts has been Seymour Papert, who generated some interesting challenges for educators with his book Mindstorms just over eight years ago. Since those first challenges, the technologies, which enable the manipulation and generation of ideas, have also developed. Four to five years ago the Macintosh burst onto the scene and provided the user with a graphic interface as a standard. The user was then able to manipulate concepts visually and more intuitively than had been available on mainframes or under the mnemonic operating systems of some personal computers.

The provision of these powerful tools has enabled concepts to be understood more completely and learned more efficiently. Understanding the integral calculus of LOGO can lead to complex mathematical ideas in an intuitive context well before the student has progressed to levels of formal operational thought. Dealing with pictorial representations has also enabled the designer to present complex concepts in forms that are seductively simple to the learner. Shapes can be stretched and distorted by manipulating a "mouse" attached to "handles" of the figure. The latest graphics drawing tools use tangential line "handles" to change curvature and create complex smooth figures.

Technologies, and particularly information technologies, are at a point where they can easily integrate a variety of components into one device. With increasing power of small systems there are also other trends which predict a greater integration of technologies and a corresponding reduction in the currently considered separate hardware/communications technologies. Nicholas Negroponte, Director of the Massachusetts Institute of Technology Media Lab, has described the situation as a series of overlapping circles. Using figure 1, he indicated to senior executives in the communications industries that their strategic planning for the future should take into account the convergence of technologies and that their products would increasingly become interchangeable and 'playable' on the one computer-based system. 


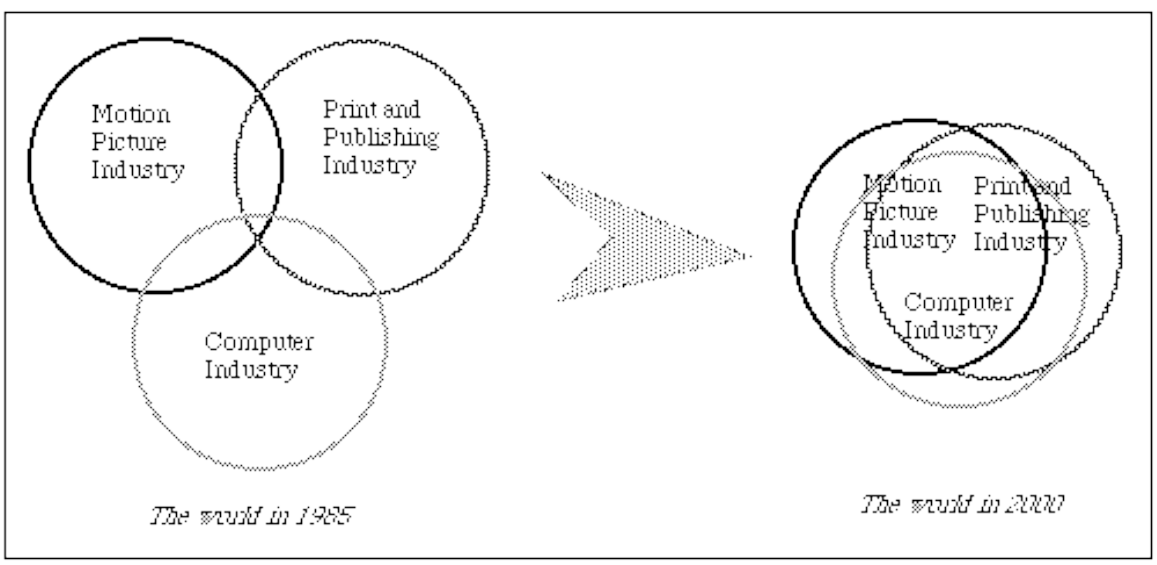

Figure 1: Converging technology industries (Negroponte, in Brand, 1988)

An excellent example of where Negroponte's conception would lead is epitomized though recent developments in personal computers, such as Steve Job's next computer, where a number of information storage devices are combined, quite literally, into one black box. These developments can prove a boon to the designer in that more senses can be employed in the learning interaction between the learner and the technology. However, at the same time they raise instructional design challenges about the way the interaction should be developed. In studies of technology-as-hardware, student learning has not been enhanced by the hardware alone, other factors, in particular the design of the learning materials using the technology, have been more important (Clark, 1983, Johnson et al, 1988; Salomon, 1979).

\section{Technology as process}

There has been a growing movement which has focused upon the technology-as-process approach. The most quoted examples have been in military andindustrial settings. Training personnel have adopted this approach to delivering complete instructional experiences. This intensive approach often tried to produce a curriculum which could be selfcontained and work without the need for an expert instructor. In the highly-focused training environment this approach is sensible; outcomes and experiences can be clearly defined, untrained instructors can present a good course, and the criteria for successful performance can be clearly stated. In the school classroom, this approach has been masked by curriculum movements. The approach has produced curriculum materials which have been only as effective as the instructional design and media selection skills of the material developers (See, Clark, 1983; BangertDowns, Kulik \& Kulik, 1985; Roblyer et al, 1988 for meta-analyses and reviews of studies). 
During the 1970s and 1980s, numerous authors have written about the technology-as-process approach to curriculum design (Reiser, 1987; Percival and Ellington, 1988). In a recent summary, Percival and Ellington (1988) outline the changing major concerns of the approach as:

- a gradual shift towards more student-centred approaches to learning, such as the use of individualised learning in its various forms.

- an ever-widening realisation that there is more to education than teaching facts, and experiences should include cognitive skills, non cognitive skills and attitudes.

- an rapidly increasing use of information technology in education and training.

While technology appears to enable more individualised learning, there is a growing trend towards group-based activities using the technology. Percival \& Ellington (1988) claim that the above trends are interwoven in simulations and games which enable the combination of cognitive and other elements in learning. Construction of computer-controlled robots can be an exercise in group co-operation as much as creative problem solving. Curriculum materials based on the technology-as-process approach often include activities which can be employed as instructional strategies for group or individuals. The career education materials Ask the Workers... (Steele, 1988) were designed to be used in both instructional strategies. Individual access to a workstation was only required for individual diagnosis.

Within this context, any technology might be described as a mediator between the three human components of the interaction; the subject matter/ content expert, the instructional designer and the learner. Technology, on its own, is inanimate and lifeless; the human manipulation of the interaction creates the power of the technology for learning. The link between the original expert and the learner can be considered to be mediated through the attributes of the technology employed and the skills of the instructional designer (who incidentally may also be the teacher or instructor). The content organisation and the attributes of the technology the designer employs to present the ideas will help or hinder the learner's comprehension of them (Salomon, (1979). Learners, in turn, have their own individual understanding or conceptual sets which they apply to the presented materials to achieve mastery of the knowledge and information presented. Engelbart (1988) illustrated the concept, when he described the attributes of a hypermedia (note 1), environment (Figure 2), which augments human capabilities. His thesis is that most human capabilities are composites; any "example capability" can be thought of as a combination of the human-system and the tool-system capabilities. This 
process is possible, given the human skills and knowledge, to employ these systems. It is this last skill-the knowledge to employ-which is a major variable in technology adoption.

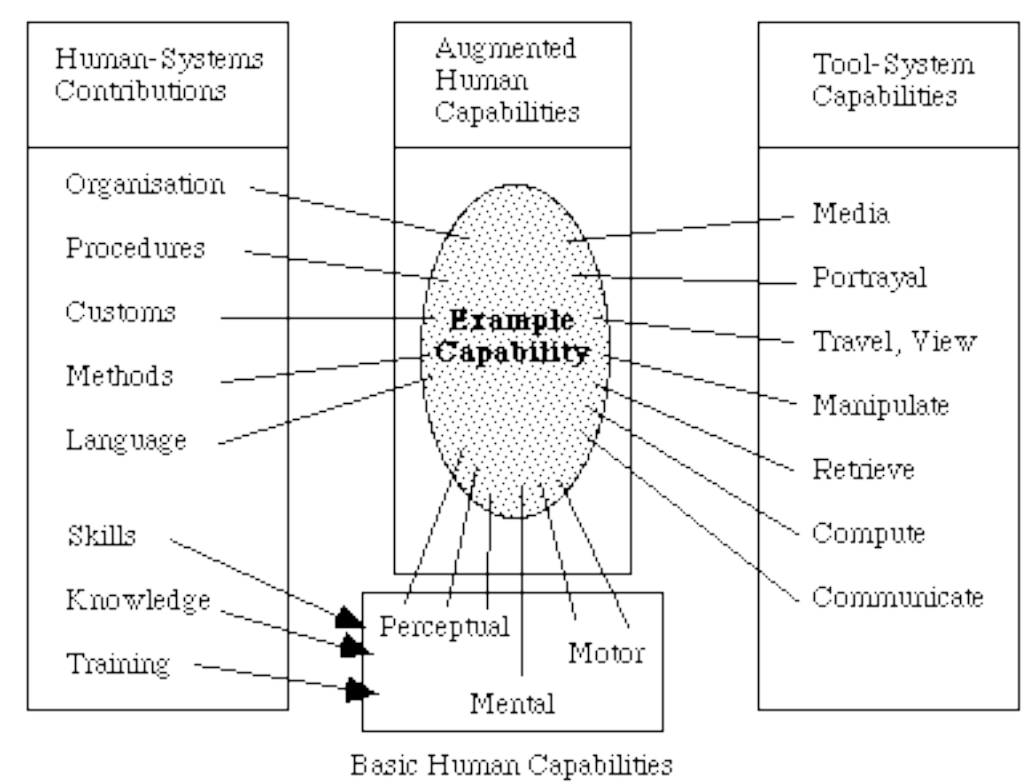

Figure 2: Extending the capabilities of the individual through technology

(Engelbart, 1988)

In order to demonstrate how the instructional designer and the learner can use appropriate technology to improve skills, conceptual understanding and the process of communication of ideas, it becomes important to examine the current conceptions of how technology might be employed and what skills are required of both instructor and learner.

\section{Technology as life}

Although computers have become relatively commonplace in the workforce and in everyday living, there still exists a comparatively large number of individuals for whom computer interaction consists of waiting while the teller completes the transaction at the computer terminal, or perhaps, watching the prices being added on the cash register while the checkout operator 'waves' the articles over the barcode reader. Those who can access their money via the electronic barking 'black box' are moving into more sophisticated levels of technology use. 
Many of those coming to terms with technology in higher education are representative of these groups. Greater emphasis is being placed on learner involvement in learning, and demands are being made for a broader knowledge base. Thus learners are being compelled to venture into areas which were once the realms of specialists. For example, work has been undertaken with interactive videodiscs (note 2) where students can explore databases of realistic situations in the security of the classroom, and the technology enables them to become involved and make decisions. These decisions can be about key issues, such as, chemical experimentation or future employment. This interaction can occur without fear of failure (Scriven and Adams (1988): Ambron \& Hooper, 1988).

Word processing and literature searching are two common examples of increasing technology use as an extension of human capabilities. Traditionally, assignments were handwritten or an author employed a typist to create a respectable assignment presentation. The proliferation of word processors has changed that. Assignments must now be at least typewritten, preferably word processed, spellchecked and, in some instances, be presented with integrated illustrations and graphics laid out using a page layout program. Hard copies are not always required either. Some instructors request assignments to be submitted on disk, or in the case of distance education, assignments can be downloaded via a modem or placed on a bulletin board.

In the area of literature searching, the contents of the school or institution's library sufficed or, if not, a researcher made an appointment with the "online search" specialist librarian to conduct a (rather costly) literature search. The advent of databases on CD-ROM (note 3) has enabled a "do it yourself" approach. This easy and cheaper alternative is encouraging academia to incorporate a more comprehensive review of the literature in areas which were once the kingdom of the textbook. Realistically though, not everyone employs technology in achieving a goal and many teachers, while using a technology at a basic functional level, do not think in terms of its potential to assist human thought and concept development. (Office for Technology Assessment, 1988; Roblyer, et al, 1988).

From the work at the MIT media lab and the growing awareness of integrating technologies such as CD-ROM, CD-I (note 4), and DV-I (note $5)$, there are predictions that, not only will the future classroom be well equipped, but these systems will also allow home use at reasonable cost. The move over the next few years will be to publish and present knowledge in these technologies (see for example, Bitter, 1988; Hativa, 1986, Hedberg, 1989).

Information technology-based, teaching materials are often confined to the role of a sophisticated presentation devices. However, with existing applications software, there is the opportunity for the student to use 
applications software packages for knowledge generation as well as knowledge presentation. (See for example, Hedberg, 1988a).

\section{Technology and the learner}

\section{Interface issues}

Unfortunately the provision of sophisticated technology has often taken for granted the human capabilities in using them. Many writers have described the complexities of the human-computer interface which can create "technostress" - the problems associated with living in a world where technology dictates the speed and style with which tasks are done (Brod, 1984). For example, Shneiderman, $(1982,1987)$ describes the problem as it applies to the computer-user:

Frustration and anxiety are a part of the daily life for many users of computerised information systems. They struggle to learn command language or menu selection systems that are supposed to help them to do their job. Some people encounter such serious cases of computer shock, terminal terror, or network neurosis that they avoid using computerised systems. These electronic-age maladies are growing more common; but help is on the way!

...the diverse use of computers in homes, offices, factories, hospitals, electric power control centers, hotels, banks, and so on is stimulating widespread interest in human factors issues. Human engineering, which is seen as the paint put on the end of a project, is now understood to be the steel frame on which the structure is built (Shneiderman, p. v, 1987).

While new and exciting aspects of information technology and its use are constantly being brought to the attention of the higher education community, the human-technology interface seems to have attracted attention in education only in recent years (e.g. Barrett and Hedberg, 1987; Shneiderman, 1987). This issue becomes more important when considered in the light of the problems faced by teachers as learners as they attempt to understand and use the technology as a tool. In summarising the state of technology adoption by teachers, the Office of Technology Assessment (1988) found that interactive technologies take more time and effort to learn than many other curricular innovations, and their use made teaching a bit tougher, at first. The choice of an appropriate technology for learning might focus on these issues, if more general use is to be made of the technology by teachers.

\section{Learner control}

A study carried out by McNamara (1988) is typical of a number of studies of teachers working in technology-based contexts. She gathered data working with teachers as students in a self-instructional computer environment. Teachers (with differing levels of computing experience) 
were asked to complete a set of tasks requiring the acquisition of information from a database on CD-ROM. She identified three areas of technology problems, which hindered the learning progress: Computerbased (procedural, operational) problems, application package (program) problems and human related (attitudes, expectations) problems.

Several participants had never used a computer before. Not only was the idea of a data storage on a small disc unfamiliar to them, so too was the means of accessing the disc. Some of the most prohibiting factors were the necessity of knowing specific identifying words, the need to press specific keys for the generation of particular information, and the methods of correcting errors in typing or input. At a deeper level, several participants were willing to accept the first instance of information which appeared on the screen, without checking for details or the appropriateness of the response. They firmly believed that the computer could not err - (even if the error was in human input), and therefore the information must be correct. Beside the need for keyboard skills, which created a barrier to effective use of the technology, many participants concentrated more upon following correct procedures, rather than the information being presented. Optimistic assumptions about teachers' ability to use technology frequently cause problems with the instructional strategies in which the technology is employed.

A related problem has been that some current application software appears to the novice user to have been written by those "in the know". Although most applications programs incorporate "help" mechanisms (approximately twenty-two screens of help were found in one database program), these resources are beyond the grasp of the novice user or one unfamiliar with the "language" of how to get to, and be able to read the "Help" file.

The most important catchcry of the computer-based education enthusiasts has been learner control. However, while there are numerous studies indicating its importance for motivation and efficient learning, its actual implementation in courseware is often only lip service. Learners, to take control over their learning experience with technology, still need to understand how the software they are using works and where they stand in their performance so that they can make informed decisions about where to venture next. The current enthusiasm for Hypercard (note 6) as a medium for exploration is based on the ability of the keen learner to choose a path and enjoy the options. At any moment the student can review where they have been and jump directly to a particular screen (through the "recent" review function); this degree of flexibility and graphic summary of progress has either not been possible before in courseware or simply too difficult to include. While its impact has not been fully explored, the opportunity for a "hyperview" of their learning 
sequence does enable greater control of what and how some things can be learned. An extensive summary of the hypermedia options becoming available has been provided by Ambron and Hooper (1988), and this challenges the developers of computer-based software to conceive of different formulations of instructional sequences in place of the routine drill and practice, tutorial, simulation, and problem solving strategies of the past.

\section{Learning styles and technology}

A brief examination of some of the assumptions regular users of the technology make, highlights some of the issues which must be faced by designers of materials using information technology in education (Hedberg \& McNamara, 1989). While perhaps a minor consideration, even the placement of the power switch on the computer can be a deterrent to those unfamiliar with the equipment. When using software programs, the differences between expert and novice users become even more pronounced. Most obvious has been the time taken to complete tasks which increases as the response required by software becomes more obtuse and less inherently conceptual (Hedberg \& McNamara, 1985). With regard to differences in learning styles and personality approaches to learning, those who like to know what's happening each step of the way have greater difficulties in using the technology on their own than those whose approach to learning allows them to simply 'press on regardless' without the need of knowing what the computer is doing. Those who see the challenge as exciting and a new learning experience have considerably fewer frustrations than those for whom the thought of sitting at a workstation is tantamount to torture. How often does one have the time to thoroughly examine a package or read all the associated documentation before it must be used? (Providing of course that the documentation can be understood!)

There is a growing realisation that the forms of software presentation can now adapt to the modes of representation and learning styles preferred by individual learners. Visual learners can convert data tables into graphical forms, haptic learners can use robotics to see, touch and feel the meanings of computer commands and their effect on an object. The link between formal logic structure and physical representation can be explored in terms of a functional relationship. In the mathematical curriculum it is possible, with software such Geometric Supposer, Function Builder, to investigate and manipulate ideas in a one-to-one relationship. A change in the mathematical function will be shown by a change in its graphical representation, and modifying the graphical representation will produce a corresponding change in the function. On a more concrete level, the work by Papert and his colleagues with Lego LOGO also enables this link to be investigated (Papert in Brand, 1988). 


\section{Preparing to use information technology}

The problem at the moment appears that most teachers (and possibly also designers) do not really understand enough about information technologies even when they claim to be users. In one US study, high school teachers who claimed that they were "frequently" or "often" users of computers in their teaching, mainly used the technology in a routine fashion. Most teachers used the technology with a drill and practice instructional strategy, usually with routine or externally prepared software. Few teachers used the more sophisticated or open-ended strategies. (Steiglitz \& Costa, 1988)

The use of the technology is not purely a function of the availability of equipment, it is also a problem of understanding the technology as a tool for thinking. While it might never be expected that all teachers will use the technology as a tool for everyday knowledge generation and presentation, special groups such as mathematics and science teachers do have some conceptual advantages in using the technology from a discipline point of view. However, that alone is not sufficient. In describing the effectiveness of an interactive videodisc mathematics lesson, Carnine, et al (1987) emphasised the importance of instructional design in the materials which made them more effective than teachers working by themselves with a computer. These authors emphasised that instructional design skills were equally as important as the provision of the curriculum materials.

Even with less sophisticated materials, such as the production of class handouts, there are new skills involved in the preparation of printed curriculum materials using the skills of typist/graphics composer/page layout compositor. The microcomputer has required a re-working of tasks and roles. The availability and accessibility of this technology has enabled individuals to work directly with the material which is going to be used in the teaching process. The immediacy and closeness with which individual authors can work on their material has meant that high quality materials can be presented quickly and designed to improve learning and increase their effectiveness.

\section{Teaching for understanding}

In rethinking the approach to technology in teaching, the Educational Technology Centre (ETC) at Harvard University was structured as a collaborative consortium of teachers and researchers with expertise in areas as diverse as subject matter, cognitive psychology, teaching, curriculum, instructional design and educational media. Key in their pedagogical approach to each research study was a concern for teaching for understanding - in which knowledge of the phenomenon under study was analysed through key concepts, current scientific and mathematical explanations of them, and the relationships among data, concepts, and 
explanatory schemes. While not entirely novel, this approach enabled the teams of researchers, in collaboration with practising teachers, to develop some important materials which extended the student's understanding of the subject they were studying.

Taking account of students prior conceptions. One of the key elements in the materials designed was the deliberate linking of previous learning by means of the technology to scientific method and theory, so that the materials created an environment in which new data and phenomena could be transformed from naive understanding into more lasting and sophisticated ideas. In many projects technology enabled students to work with their own levels of understanding and with representations of knowledge with which they were comfortable.

Integrating directed instruction and inquiry learning. One of the concerns with instructional strategy led the team to apply a different approach to those previously advocated by the proponents of microworlds (Papers in Brand, 1988). The mix in instructional strategy was to overcome the problems of extremely open-ended environments which, they believed, rarely led to students reconstructing concepts that mathematicians had taken centuries to devise. By designing materials which employed technology in a hybrid of direct instruction and inquiry learning, teachers helped students develop and test their own ideas. Commercially available software was employed in this type of activity.

Teaching how knowledge is generated. One ETC project, the Nature of Science Project, used a variety of resources to produce an understanding of scientific thinking within the context of specific phenomenon. An interactive videodisc was used to investigate several "black box" problems. With this technology a series of conjectures could be investigated without expensive experimental equipment and the results of each manipulation of variables could be easily demonstrated. When this introduction to the experimental method was combined with real experimentation, students moved away from narrow beliefs about science to understand that it originates in the mind of the scientist and that it involves persistent examination of ideas.

These concepts about teachers and teaching strategies are not unique to this series of projects. The work at the MIT Media Lab and their associated elementary school has created similar environments for learning, with success for learners at different levels of ability. The outcome of all such activity has been to re-examine the role the teacher and technology can play, no longer can the teacher simply relinquish his/her presentation to an audiovisual presentation device, the teacher must take an active role in supporting the inquiry. 


\section{Technology supply issues}

Many of the detractors of the use of technology in the classroom complain that either there will not be enough equipment to go around in each class or the available software will never cover all the curriculum. To both of these concerns, the reply must be that not everyone needs access all the time. When paired with the right combination of group and individual activity, teachers can manage a class on ratios of one machine to ten or so students. Four or five machines with associated generic applications software can provide a range of experiences over the time the class is in the room. Several studies have been conducted with a small number of computers in regular classrooms with great success (Trollip \& Alessi, 1988).

As to the other aspect of insufficient curriculum software, many writers have promoted the use of templates for applications software (Hedberg 1988a). What is more important is the structure of the exercise and the ability of the student to change elements in the model. When the choice of appropriate hardware is linked with potential software, then great advances can be made at very little cost and with little time spent in software development. Hypercard and Linkway are two programs which enable users (whether they be teachers or students) to design a series of experiences which can present ideas and manipulate them cheaply with the minimum of programming effort. Further, as it is possible to exchange software produced on these systems, the cost of running a range of curriculum materials is the cost of the disk. Recently, Club Mac released a CD-ROM of all its software. Only one would be needed at each school, as most material is in the public domain. Further, simple authoring software is becoming available in this format, allowing teachers or typists to input tests and experiences which can be quickly modified.

Compatibility issues. Over the years most educational systems, whether they be State Education Departments, universities or individual schools, have sought to simplify the process of compatibility by insisting on one or two machines. This is becoming less and less of a major problem. With bulletin boards it is a simple matter of copying files from one computer to the other. Often software is written in languages which enable transportability of software such as "C". This trend, when matched with the growing capability of reading and writing magnetic media from any of the three main systems (IBM, Apple II, or Macintosh) and the links between major mainframe and micro manufacturers (e.g. Digital and Apple), would indicate that there should be little real concern for constraining unified hardware requirements.

\section{Technology to support professional performance}

As all professionals start to see information technology as an extension of their own professional operation, appropriate support for technologically interwoven environments can occur. Unlike other professionals, teachers 
often see themselves as isolated from their peers, their interest in constructing curriculum themselves or developing alternative instructional materials (other than a traditional textbook) is severely constrained by lack of time for anything other than the most basic classroom maintenance, leading in turn to an overwhelming demand for the practical in approaches, materials or hardware (Jackson, 1986; Kerr, 1989).

\section{Technology and instructional design process}

Throughout the preceding discussion, the examples of courses employing technological delivery sought to ensure that participants, not only have access to appropriate and compatible technologies, but also that they are aware of, understand, and are comfortable and competent with the delivery technology to ensure its smooth use. The focus was on the information delivered via the technology rather than on the technology itself. Packages have been viewed as a means to an end rather than as the most important element of the interaction. In terms of personality differences and the implications of differing learning styles, courses and packages utilising technology-based materials must incorporate design measures which offer alternate paths and options for a successful learning encounter (Ambron \& Hooper, 1988).

Laurillard (1987) has spoken of the development of multifaceted design models and Hedberg (1988a) has mentioned the use of templates as simple ways that link the use of technology to regular tools which are in common (preferably daily) use by the learner. Such a concept needs first to examine the reasons for using technology in the teaching/learning process. For example, the use of the simple device of a spreadsheet with a prepared mathematical model allows at least three levels of processing. First, a learner may type their own numbers into a prepared pro forma, the package will calculate according to the prepared algorithms and changes in different elements will show a relationship between inputs and results. Changing the inputs allows the learner to model different results based on the input assumptions. A second level might involve the translation of the numbers into another form of representation such as a chart. This second level may have been already prepared by the instructor and the links simply updated as the learner changes the numbers in their first pro forma, or the reamer might use the links between spreadsheet and charting routines to clarify or further investigate relationships (especially if they are a visual learner). A third level would enable the leaner to change the underlying assumptions on which the analysis is based - the learner might decide to investigate the algorithms devised for the relationships between inputs and results. By changing the formulae, the learner can extend beyond the interaction designed by the subject matter expert and the instructional designer. At both the second and third levels, the learner is 
manipulating the technology to generate knowledge rather than simply to watch its presentation. Thus the technology allows the student to extend his or her understanding beyond the original intents.

Recent work has tried to reassess the functions of technology in terms of the type of tools required for different types of learning activities. Consider Table 1, where four key activities for teaching and learning are described - knowledge generation, knowledge presentation, knowledge communication and information management. The instructional designer needs first, to focus on the underlying learning activity, then secondly, define a link between the concept presentation and how the students must work with the information to produce their own understanding of the ideas and issues. Foremost in this design concept is the idea of allowing the student to manipulate the concepts directly, and not to have the presentation totally circumscribed by the designer, who might decide to present information in a single conceptual model.

Thus the model presented here is concerned with two basic functions of a technology for learning-teaching/learning activity and form of knowledge representation. Additionally, because learning may occur at a time or distance remote from the tutor, knowledge must also be communicated with others. The communication of results, questions and corrections between tutor and learner, or amongst students, is of particular interest, and technology can influence and assist the quality of this interaction. As mentioned previously, bulletin board software can be used to generate insights beyond the prepared brief of the designed materials.

The last teaching/learning activity illustrated in the model indicates the important management function involved in all materials to be used in learning. Personal productivity software, when linked together, can provide a useful organising force for tutor, designer and student, especially for time management or idea generation.

Each of the four teaching/learning activities can use technology in a variety of forms. Each different form is appropriate or needed for the ideas or concepts to be understood by the learner. Using current information technology we are no longer constrained to the simple verbal form. Mixtures of sound, music, words, pictures or moving sequences can be integrated into each teaching/learning activity. With computer control of external devices, it is possible to manipulate objects in three dimensional space and to link them with graphical or numerical representations.

Richey (1986) emphasised that instructional design has been distanced from teachers when she opened her book:

Planning instructional programs and materials has been separated from the jobs of those who actually deliver the instruction in a growing number of 
situations .... The dichotomy between instruction and instructional design ... is ... influenced by different theoretical orientations and different practice histories (Richey, 1986, p.2)

Table 1: Applying information technology to teaching and learning (Hedberg \& McNamara, 1989)

\begin{tabular}{|c|c|c|c|c|c|c|c|}
\hline $\begin{array}{l}\text { Tesching' } \\
\text { Lesring } \\
\text { Activity }\end{array}$ & Aursl & Visual & Verbal & Humericsl & Felationsl & Logical & Fhysical \\
\hline $\begin{array}{l}\text { Knowledge } \\
\text { generation }\end{array}$ & $\begin{array}{l}\text { Sound } \\
\text { editing and } \\
\text { digitising } \\
\text { programs } \\
\text { Musis } \\
\text { programs }\end{array}$ & $\begin{array}{l}\text { Musis } \\
\text { programs } \\
\text { Graphios } \\
\text { programs } \\
\text { Animation } \\
\text { Frograms }\end{array}$ & $\begin{array}{l}\text { Word } \\
\text { processing } \\
\text { Fage Layout }\end{array}$ & $\begin{array}{l}\text { Spreal- } \\
\text { shents } \\
\text { Databases }\end{array}$ & $\begin{array}{l}\text { Databases } \\
\text { Frogram- } \\
\text { ming } \\
\text { Languages }\end{array}$ & $\begin{array}{l}\text { Frogran- } \\
\text { ming } \\
\text { Languages }\end{array}$ & $\begin{array}{l}\text { Fohotios } \\
\text { Keyboards } \\
\text { Lego } \\
\text { LoGo } \\
\text { Fhysios } \\
\text { data capture } \\
\text { sotware }\end{array}$ \\
\hline $\begin{array}{l}\text { Knowledge } \\
\text { presentation }\end{array}$ & $\begin{array}{l}\text { Music } \\
\text { Frograms } \\
\text { Speech } \\
\text { syuthesis } \\
\text { programs }\end{array}$ & $\begin{array}{l}\text { Music and } \\
\text { Sound } \\
\text { programs } \\
\text { Graphios } \\
\text { programs } \\
\text { Animation } \\
\text { Frograms } \\
\text { Authored } \\
\text { CAI } \\
\text { DV-ICD-I } \\
\text { Luteractive } \\
\text { Video (diso) }\end{array}$ & $\begin{array}{l}\text { Authored } \\
\text { CAI } \\
\text { Programs } \\
\text { Word } \\
\text { propessing } \\
\text { Fage Layout } \\
\text { CD-I } \\
\text { (books) } \\
\text { DV-I }\end{array}$ & $\begin{array}{l}\text { Drill \& } \\
\text { Fractice } \\
\text { Spread- } \\
\text { sheets } \\
\text { Databases } \\
\text { DV-ICD-I } \\
\text { Interactive } \\
\text { Videodise }\end{array}$ & $\begin{array}{l}\text { Authored } \\
\text { CAI } \\
\text { Databases } \\
\text { Frogram } \\
\text { ing } \\
\text { LaInguages } \\
\text { CD-ROM } \\
\text { databases } \\
\text { DV-ICD-I } \\
\text { Iuteractive } \\
\text { Videodiso }\end{array}$ & $\begin{array}{l}\text { Authored } \\
\text { CAI } \\
\text { Frogram m- } \\
\text { ing } \\
\text { Languages } \\
\text { CD-ROM } \\
\text { DV-I'CD-I } \\
\text { Interactive } \\
\text { Videodiso }\end{array}$ & $\begin{array}{l}\text { Fobotics } \\
\text { Computer } \\
\text { as a } \\
\text { scientific } \\
\text { instnument } \\
\text { Hypermedia } \\
\text { Iresentation } \\
\text { CD-ROM } \\
\text { DV-ICD-I } \\
\text { Interactive } \\
\text { Videodiso }\end{array}$ \\
\hline $\begin{array}{l}\text { Knowleder } \\
\text { comm unication }\end{array}$ & $\begin{array}{l}\text { Hew } \\
\text { generation } \\
\text { woine mail } \\
\text { Hatursl } \\
\text { langugge } \\
\text { processing } \\
\text { speech } \\
\text { syuthesis } \\
\text { Musio } \\
\text { programs }\end{array}$ & $\begin{array}{l}\text { Graphics \& } \\
\text { Animation } \\
\text { Fresent- } \\
\text { ation }\end{array}$ & $\begin{array}{l}\text { E-IMil } \\
\text { sotwase } \\
\text { Communi- } \\
\text { cations } \\
\text { Sottware } \\
\text { DV-I } \\
\text { CD-I } \\
\text { CD-RoM } \\
\text { Video }\end{array}$ & $\begin{array}{l}\text { Fublic } \\
\text { Databases } \\
\text { DV-I } \\
\text { CD-I } \\
\text { Database } \\
\text { programs }\end{array}$ & $\begin{array}{l}\text { Databases } \\
\text { Fublio } \\
\text { databases } \\
\text { CD-I } \\
\text { databases } \\
\text { Frogramm- } \\
\text { ing } \\
\text { Languages }\end{array}$ & $\begin{array}{l}\text { Mainframe } \\
\text { metworks } \\
\text { linked by } \\
\text { modem } \\
\text { Fublic } \\
\text { bulletin } \\
\text { hoards } \\
\text { Hatural } \\
\text { lingusge } \\
\text { processing }\end{array}$ & $\begin{array}{l}\text { Froprio- } \\
\text { ceptive } \\
\text { Recording } \\
\text { Videodise } \\
\text { CD RoM } \\
\text { DV-I } \\
\text { Actus } \\
\text { medis }\end{array}$ \\
\hline $\begin{array}{l}\text { Ifformation } \\
\text { Insiagement }\end{array}$ & $\begin{array}{l}\text { CD-ROM } \\
\text { CD-I } \\
\text { DV-I } \\
\text { Andio } \\
\text { CD } \\
\text { Magutio } \\
\text { media }\end{array}$ & $\begin{array}{l}\text { CD ROM } \\
\text { CD-I } \\
\text { DV-I } \\
\text { Intersotive } \\
\text { Videodiso } \\
\text { Maguetic } \\
\text { media }\end{array}$ & $\begin{array}{l}\text { CD-ROM } \\
\text { CD-I } \\
\text { DV-I } \\
\text { Intersotive } \\
\text { Videodiso } \\
\text { Maguetio } \\
\text { media }\end{array}$ & $\begin{array}{l}\text { CD-ROM } \\
\text { CD-I } \\
\text { DV-I } \\
\text { Irtersotive } \\
\text { Videodise } \\
\text { Meguetio } \\
\text { media }\end{array}$ & $\begin{array}{l}\text { Databases } \\
\text { Student } \\
\text { Testing } \\
\text { Frograms } \\
\text { CD-RoM } \\
\text { CD-I } \\
\text { DV-I } \\
\text { Interactive } \\
\text { Videodise } \\
\text { Magnetic } \\
\text { media. }\end{array}$ & $\begin{array}{l}\text { Databases } \\
\text { Student } \\
\text { Testing } \\
\text { Frograms } \\
\text { CD-Rom } \\
\text { CD-I } \\
\text { DV-I } \\
\text { Intersotive } \\
\text { Videodise } \\
\text { Magretic } \\
\text { media }\end{array}$ & $\begin{array}{l}\text { Storsge } \\
\text { devices } \\
\text { CD-Rom } \\
\text { CD-I } \\
\text { DV-I } \\
\text { Videodise } \\
\text { Videotape } \\
\text { Mequetic } \\
\text { media }\end{array}$ \\
\hline
\end{tabular}


Producing materials can occur through enthusiastic teachers, through teacher educators or as demonstrated by the ETC example at Harvard, through a collaborative approach of both. Models of instructional) design abound in the literature, and most of the recent attempts to link technology with practice have simplified the process and reduced the complexity of previous behavioural prescriptions. Emphasis is upon structuring the curriculum so that it can be represented by simple "epitomes" (see Reigeluth, elaboration theory, 1987) and graphical links between concepts and motivating environments (Reiser, 1987). Many organisations who must manage the production of learning resources operate on the just-in-time method for their generation. The cost of inventories, the complexity of multi-media storage, and the deterioration of electronic media with poor storage and time has meant that many curriculum packages are produced on-demand. These factors do not necessarily require a centralised production source. Most reasonably large organisations already possess the infrastructure to produce materials without the need for further bureaucratic centralisation. In fact, the notion is generally antagonistic to trends of development in information technology and the way in which people adapt and implement new technology. However, there is definite need to assist with the identification of good products which are often hidden in a growing mountain of alternatives. Instant access to information about and evaluations of packages, together with cheap copies of their associated documentation, can be made available through public bulletin boards and/or distributed through CD-ROM or other large database storing technology.

Propinquity is also a major factor in producing a product. The fact that the subject matter expertise, the design expertise and a computer are frequently within walking distance of each other will help the production of materials in ways not envisaged in the traditional bureaucracies of curriculum development centres. However, it is very unlikely that any economies can be achieved without some coordinated curriculum development of quality and with an eye to appropriate technology for the learning task.

\section{Hardware choice}

The use of technology, especially the development of computer-based technologies to enhance human abilities, is still largely in its infancy. Very rarely do we see a co-ordinated, integrated approach to the production of the written teaching materials upon which most of our institutions so heavily depend. Even computer systems are not always networked to share the use of their resources between and among all groups on campus, especially the so-called "non-computer" departments. Activities such as electronic mail, database access, and smaller things such as, shared laser printer use, and access to existing information databases such as the 
library catalogue and circulation systems are not always possible with the existing networks and technology. Often the problems of adding an extra telephone line into an office for modem links and facsimile links are too difficult for existing bureaucracies. Adding technology involves rethinking the total system so that the microcomputer does not simply replace the old electric typewriter. Personal computing technology has forced the total work and information flow of an individual department to be rethought, simplified, improved or modified. Current trends in software development have emphasised the group linked through new networks ideas and shared resources. Groupware might become a useful tool for teachers who employ the technologies in their classrooms. These issues need to be addressed in a technology curriculum for teachers if they are to feel that the technology will assist them to undertake their professional tasks (Office of Technology Assessment, 1988).

It is difficult to predict future hardware formats and the most appropriate technology in which to develop resources. At the moment, the push is to use pre-recorded formats (usually optically encoded), such as CD-ROM, although, the recently released NeXT computer uses an optical read-write system holding about 250 megabytes. WORM technology exists to enable writing data once on optical media and then being able to read many times. Entire manufacturing plants are run on WORM technology. No paper is generated; everything is added and changed in centralised filing systems. However, most current projects have considered interactive videodisc which requires less change to existing systems of recording and distribution. Publishing companies are considering CD-I (digital, interactive, multimedia systems) as a potential device for distribution of interactive training, reference books, albums, home learning and do-ityourself learning, either with or without the computer (in the latter case the technology would be built into the system). Some commercial companies promise DV-I with up to 75 minutes of full screen video and 3D motion pictures (see discussions in Bitter, 1988; Scriven and Adams, 1988). Whatever the final hardware choice, the growing trend toward file conversion and similar magnetic media formats will probably continue for the next few years. This development alone will enable exchange of software between the major systems.

\section{Designing intelligent software}

Roblyer et al (1988) recently completed a meta-analysis of 85 studies on learning from computer-based materials carried out between 1980 and 1987. They found that, in general, computer-based instruction was more effective than traditional or other media-based delivery, although they did indicate that it depended on the strategies employed in the subject. For instance, in science, simulations had a high positive effect and this was 
due to the particular type of instructional strategy. LOGO applications were more promising than those which used unstructured computer assisted instruction. In their analysis they indicated that application type does not have much impact in mathematics but improved learning occurred with simulations and new forms of representation in Language and Reading. These authors classified software application types into two main areas:

I - drill and practice/tutorial

II - simulation and new forms of representation.

Recent educational software has provided instruction for both student and teacher, and it supports activities which are seen as important by the instructor (see for example, Geometric Supposer [Schwartz \& Yerushalmy, 1985] and The Voyage of the Mini [Gibbon in Ambron \& Hooper, 1988]).

The design of an "intelligent" software does not necessarily mean the move to more complex artificial intelligence systems; it could mean simply using the ideas of good game design which engages students by providing fantasy, creativity and challenge (Malone, 1981). Simulations should be open-ended and allow students to generate knowledge rather than manipulate the parameters (Hedberg,1989b; Goldenberg, 1988). Extending the range of experience through the use of peripherals such as CD-ROM and videodisc should be seen as commonplace rather than special events. The work undertaken with the only Australian videodisc system produced specifically for schools (Steele, 1988) has demonstrated that the systems can work. However, it does require the vision of educational departments, intelligent interactive media design, and a small additional investment in a distribution technology which is more robust and of higher quality than anything currently available.

The move from traditional conceptions of what educational software might present with hypermedia involves greater control for teachers and modifiability of the software (Hativa, 1986). Early concepts of software saw instructional strategies being clearly defined and fixed within each software package. Recent systems have also included artificial intelligence components which enable strategies to be more closely matched to the learning style (Criswell, 1989). Even without artificial intelligence components, the move into Hypertalk language structures has enabled greater flexibility in design and the use of environments. Certainly, the addition of interactive videodisc and CD-ROM is a simple task and one that extends the capabilities of the software design (see Fielded and Steele, 1988, Ambron and Hooper, 1988, Hedberg, 1985). 


\section{Guidelines for selecting future learning technologies}

\section{Alternative strategies for reaming resource development}

Major problems with any technology gaining acceptance by the designer have been the perceived threats and advantages, its ease of use and the complexity of producing materials. The technologies with which we deal today are certainly more complex than those of yesterday. The design requirements for hypermedia go beyond the linear models which were once the mainstream of curriculum development and instructional design courses. Alternative strategies need to be developed which focus on learner needs. Even the simple task of producing some handouts with a page layout program requires that the designer know about graphic design layout, instructional design of text for learning, and the operation of the computer software. This combination of skills goes beyond the cottage industry approach. The complexity that these systems allow has created the need for improved and appropriate instructional design skills.

\section{Designing infusible materials}

While not underestimating the logistical challenges of acquiring, installing and scheduling access to hardware, many of the Harvard (ETC) projects have focused upon the importance of this task in moving the innovation beyond the mechanical into the routine. Instructional materials - such as problem sets, teaching aids and lesson plans - have been found necessary to link the software to the curriculum without taking control and constraining the use of the materials (ETC, 1988; Kerr, 1989). Research on the use of innovative materials by teachers has found that computer-based lessons are not self-implementing; indeed in the Harvard projects they found that:

For many teachers, acquiring the knowledge and skills necessary to teach for understanding involves a subtle but important shift in beliefs. Reinforced by the structure and culture of their school settings, many teachers believe their role is to transmit knowledge, as formulated and presented in textbooks. To engage students in a process that includes forming, testing and critiquing hypotheses, teachers must accept the value of a more flexible set of teacher and student roles, and adopt a broader view of knowledge, teaching and learning (ETC, 1988, p. 20.).

The importance of teams which use instructor and instructional designer's skills appropriately has been mentioned by several authors (ETC, 1988; Kerr, 1989; Pea, 1987). However, with the developing technologies, there are possibilities of sharing and extending the links between teachers as well as between teachers and material developers. Creating a shared environment where software is linked to the curriculum and available at the cost of the disk, will help extend the repertoire of each technologyusing teacher. 
Throughout the preceding discussion, there have been a number of examples which indicate that media can provide a unique and useful contribution to a concept presentation. Of particular interest are its abilities such as linking multiple representations of a concept and linking physical demonstrations through robotics or hypermedia to their theoretical counterparts.

\section{Technology and the creation of ideas}

Technologies are not sufficient in themselves, effort must be made to match curriculum ideas with appropriate technology:

Simplistic software design or thoughtless use of computer graphing in classrooms may further obscure some of what we already find difficult to teach. On the other hand, thoughtful design and the use of graphing software presents new opportunities to focus on challenging and important mathematical issues that were always important to our students but were never accessible before. (Goldenberg, 1988, p. 135)

Many of the popular descriptions from the work of Seymour Papert have included descriptions where one student suddenly became the "expert" for some time and, for one brief shining moment, was looked up to by their fellow students (Papert, 1980; Papert in Brand, 1988). The environment provided by Lego LOGO and some multimedia software packages can provide for the social aspects of learning.

Improved student performance was experienced in a videodisc based lesson on fractions. Carnine et al (1987) put this effect down to a number of factors, especially, the carefully selected curriculum and the teaching strategies which fostered high levels of student engagement and success. The teaching strategies employed included a concern for example selection, an explicit teaching strategy and discrimination practice to reinforce the concepts. Carnine et al claimed that the instructional design of the videodisc was critical in the development of improved student learning. All too often they felt that the use of inappropriate elements of design in poorly conceived materials interfered with or contradicted the intent of the curriculum. Importantly in their study, they were concerned for the use of the technology with a group based on the research summarised by Bangert, Kulik and Kulik (1983) which found there were often stronger effects for group learning than when the same materials were used individually.

\section{Linking multiple representations}

One of the most important aspects of many areas of learning is the need to understand different representations of the same knowledge. Different representations of a complex idea, such as a ratio, or algebraic function, emphasise different aspects and encourage different types of analyses. 
Technology can assist as an extension of human capability by moving between graphical and algebraic representation and back again. It has long been realised that students differ in their ability to interpret and use different representations, thus this ability to move dynamically between them can provide new insights for students with carefully designed software (Pea, 1987). The word problems team of ETC led by James Kaput $(1986,1987)$ used the computer's representational capacity to help students master word problems involving rates and ratios. This difficult area often has arithmetic which is counter-intuitive, and the project developed a software environment which allowed four visual representations of the problem: a concrete representation using diagrammatic cells, a table of data, a coordinate graph with the ratio as the slope, and algebraic equations. The technology allows any or all of these representations simultaneously and changes in one can be viewed in the others. Thus the technology was used as a "learning ramp" which enabled the fourth-tosixth grade students to move from the more easily grasped iconic representation to the more abstract and mathematically more powerful representations.

Representational correspondence can also be used to effect when dealing with difficult-to-grasp concepts such as the notion of a variable. With well designed software it is possible to create new concepts using both abstract and concrete models (Goldenberg, 1988, Janvier, 1987).

\section{Extending the range of manipulable objects}

Hypermedia and robotics (such as Lego LOGO) enable the student to go beyond abstract ideas (refer to the examples in Ambron and Hooper, 1988; and Schoenfeld, 1987). Computers can also enable the student to manipulate other objects which would otherwise be intangible and this element, in itself, makes the technology involving for students (Goldenberg, 1988, Papert in Brand, 1988).

\section{Using software to reflect learner thinking}

Windows (sections of the screen in which one program or file is operating) in current software enable the instructor to investigate how their students are dealing with different aspects of a problem. Multiple windows enable many applications and files to be shown simultaneously or contiguously on the one screen. With multi-tasking, computers can refresh each window as appropriate, thus changes in one are demonstrated immediately on the other.

There are a number of unresolved questions about the use of windows in educational software, especially how the user comprehends how different windows relate and how consistent is the interpretation. Consider for example, overlapping windows versus tile windows (non overlapping segments of one screen) - often it is easier to understand what is 
happening if a number of things which are happening simultaneously occur always in the same part of the screen. This means a more expensive screen system and certainly a higher resolution system. Many of these issues have not been investigated with non-expert audiences, the research on human factors to date being largely related to business and military applications.

To improve the learning experience, software that enables the learner to have control over more than parameters is to be preferred. Students need to be able to control the underlying function as well as the parameters which might be the subject of a constrained set of experiences (Goldenberg, 1988; Kulik \& Bangert-Downs, 1983-1984). A few years ago, the Curriculum Development Centre in Canberra was interested in a small package which simulated a fishing village economy of a Pacific island. The materials were designed to include a number of graphics, but the interaction was purely setting the values of three parameters and watching the wealth of the community and the size of the fishing fleet change as the parameters varied. Students were not able to examine the functions on which these relationships depended, a short-sighted design. It would have been just as easy to use a spreadsheet template and allow the students to change values, as well as the functions, and view the outcomes in a graphical or numerical form. This approach is possible using commercial spreadsheet programs at a fraction of the cost of distributing specially coded software written in BASIC and only running on the one computer. Thus designing a spreadsheet template would have taken less time, and could be more easily adapted for different packages and computers.

Mismatches between the representation and the concept

The relationship between a concept and its representation poses some problems for the development of clear and unambiguous concepts. Consider, the problem of a screen with a fixed (and low) resolution. The size of lines and lack of smooth continuous shapes, such as a circle, makes the mathematical concept less well represented than with other media (Janvier, 1987).

Other presentation factors in computer-based material, such as the speed of execution, may hide the development of the idea. The speed with which an object is drawn or an equation solved has often led to an emphasis on the Gestalt rather than the incremental development of the idea (Goldenberg, 1988, Schoenfeld, 1987). Some software packages have had to slow down the presentation of information so that the developmental steps can be shown.

Scale, another difficult concept, can be sometimes confused in poorly executed software. It can be difficult for some students to determine the difference between a change in scale, and "zooming" into a section of an object, where the scale is not changed, only its representation on the 
screen. This problem can be further complicated by multiple windows as mentioned above. Changes in scale are easily achieved with computers, there can be confusion between zooming-in on a scale and actually changing the scale. (ETC, 1988, Goldenberg, 1988). Scale can also be complicated with a simple change of screen size. With some computer systems, the same representations on different screen sizes will appear different sizes, and there is no continuity of experience. Some computers enable a fixed-size screen representation leading to a consistency in scale representation across different size screens.

One of the interesting concepts that computers enable learners to manipulate is the idea of the finite versus the infinite. With the technology, even the best representation is still composed of finite pixels, and there are always jumps between elements.

\section{Changing Subject Matter}

A major constraint on the provision of course materials has been the need to develop materials in areas where the subject matter is relatively fixed. However, areas such as computing are subject to constant change, and since many of the existing models for learning materials cannot cope with frequent revisions, efficient course material provision suffers in consequence. It is in these areas that changes must occur if technologybased learning materials are to be seen as credible and serve the purpose of professional development.

Consider the restructuring of knowledge which is required to develop an electronic encyclopedia (Kreitzberg \& Shneiderman, 1988). The hypermedia approach to materials design that the new technology allows creates some interesting problems for someone who previously "thumbed through" a book. Electronic media require multiple indexes to point to the information. The student cannot easily browse in the traditional sense. Browsing is possible in that several of the programs now available allow a browse function which rapidly scans each "card" in a database, and the user can click to stop the process at any time. The technique is really limited to looking at some sample items and small databases, but some users not at ease with the technology have been known to sit and watch them all in order to find just one relevant item! Students require multiple point of access and tolerance of spelling mistakes to find appropriate information. The problems of information retrieval are not insignificant, but the storage cost of multiple and idiosyncratic indexes is not beyond possibility with CD-ROM and other technologies.

\section{Getting back the excitement}

Apart from developing creative software and escaping from the pageturning boredom of a few years ago, most of the applications of technology have created a sense of exploration and provided an 
environment in which powerful ideas could be manipulated and investigated. It is in this climate that the following ideas are offered to develop a technology-based instructional design competence.

- Include training in instructional design as part of the professional development of instructors. The level of this training should not stop at simplistic levels of curriculum development, their skills should include an understanding of media, computing and the links between them which could lead to hypermedia design.

- Course development projects which employ teams of professionals (including subject matter experts, instructional designers with expertise in hypermedia design, expert instructors, programmers, etc.) on clearly defined topic areas could develop materials suitable for dissemination through shareware systems.

- Development of a research project aimed at providing high quality "stacks" of shareware programs (the term stack is used to designate a collection of ideas, cards of a database, or what might loosely be termed a program). This might involve joint investment with commercial computer companies.

- Investment in technology that can use graphics interfaces and software that is state-of-the-art rather than poor relation systems with limited memory and ability to use new integrated media delivery systems.

The challenges explored in this brief overview, however, are very difficult to ignore, the rapidity of change in technologies has been cited ad nauseam in articles by the technophiles, but the major trends toward integration of technologies over the past few years and in the way ideas are manipulated, sorted, shared and communicated, raises challenges for education and training, and instructional designers, in particular. It is too easy to join the line of incremental change and adopt current technologies and the thinking which surrounds them. The opportunity to make a conceptual leap over existing learning technologies into the world that, quite literally will be with us next year, has important consequences for professional development of designers so that they are abreast of the technology as it is implemented.

If the instructional designers are excited, then there is the chance some of that excitement and creative energy will be communicated to those who learn from the materials they design.

\section{Acknowledgements}

This paper has been based on an earlier version published as part of the Discipline Review in Mathematics and Science Education (Hedberg, 1989b). 


\section{Reference Notes}

1. Hypermedia is a term becoming increasingly popular to mean the combination of the traditional communications media (video and audio) and information technology, all connected with database style links. The links occur in multiple and complex relationships which enable any type of representation to be linked to another.

2. Interactive Videodisc is a technology which is very popular with trainers but is not as important in schools in Australia as in the United States and Britain. While it is ten years old, it provides high quality video, both full motion and still pictures. One 12 inch disc can contain 54,000 still pictures per side or 35 minutes of full motion video. Two formats, CAV and CLV, allow the video material to be presented either as still frame or motion (CAV-Constant angular velocity) or motion only (CLV-Constant linear velocity). CAV discs also provide interactive features such as slow motion, revise, and still-framing. Each frame on the disc has its own number and can be instantly accessed by either a controller on the disc player or a computer that interfaces with the disc player (thus creating interactive videodisc, or IVD). It is produced by pressing similar to the more popular audio $\mathrm{CD}$ (Compact Disc) 5 inch discs.

3. CD-ROM stands for Compact Disc Read Only Memory. It is similar to the common audio compact disc and contains approximately 550 megabytes of storage on the small silver disc. Information can be stored as images $(15,000$ images), text (150,000 pages), or sound (30 minutes). CD-ROM offers the potential to provide massive amounts of information to a large number of individuals at a relatively low price. It is the growing and preferred method for distributing public databases such as ERIC, Social Sciences Index, Science Index, and many more.

4. CD-I stands for Compact Disc Interactive. This technology is similar to the CDROM technology except that the disc is designed to show restricted motion video (digitally encoded), audio and other digital information such as programs and databases. Each level and type of information will require different amounts of storage space on the disc, therefore, careful design of the disc is essential. For instance, the audio can be specified to be at speech level, LP music quality level, or CD-A quality level. The video is digitised and if full motion is used, it is limited to 60 minutes on a quarter of the screen.

5. DV-I stands for Digital Video Interactive. This technology is similar to the CDROM technology except that the disc is designed to show full screen full motion video (compressed digitally encoded) as well as other digital information such as programs and databases. The all-digital system is interactive, allowing user control of foreground video object, text, dynamic graphics, and audio. The major advantage of DVI over other optical media is the large amount of motion (74 minutes) stored on the compact disc. This technology requires a special compression/decompression technique. Using large mainframe computers, the digital video and audio data are compressed so that fewer bits are required for storage. Each time the DVI is played, the compressed data must be decompressed in real fume. This is accomplished by two special computer chips. The initial market for DVI is the military and industry, where large amounts of high quality video are needed for realism in training simulations.

6. Hypercard is a low cost program for the Apple Macintosh which allows multiple links between "cards" of information. These cards can contain graphical, numerical and textual information, and attached to each might even be some sound or vision through videodisc or some other optical storage system. 


\section{References}

Ambron, S, \& Hooper, K. (Eds.). (1988). Interactive Multimedia: Visions of multimedia for developers, educators, and information providers. Redmond, WA: Microsoft Press.

Bangert-Downs, R. L., Kulik, J. A., \& Kulik, C. L-C. (1985). Effectiveness of computer-based education in secondary schools. Journal of Computer-Based Instruction, 12(3), 59-68.

Barrett, J. and Hedberg, J. G. (Eds.) (1987). Using Computers Intelligently in Tertiary Education. Sydney: ASCILITE.

Bitter, G. G. (1988). CD-ROM Technology and the classroom of the future. Computers in the Schools, 5(1/2), 23-34.

Brand, S. (1988). The media lab. New York: Penguin.

Bright, G. W. (1987). Computers for diagnosis and prescription in mathematics. Focus on Learning Problems in Mathematics, 9(2), 29-41.

Bright, G. W. (1989a). Teaching mathematics with technology: Logo and geometry. Arithmetic Teacher, 36(5), January, 32-34.

Bright, G. W. (1989b). Teaching mathematics with technology: Numerical relationships. Arithmetic Teacher, 36(6), February, 56-58.

Brod, C. (1984). Technostress: The human cost of the computer revolution. Reading, MA: Addison-Wesley.

Burke, J. (1986). The day the universe changed. Boston: Little, Brown and Company.

Carnine, D., Engleman, S., Hofmeister, A., \& Kelly, B. (1987). Videodisc instruction in fractions. Focus on Learning Problems in Mathematics, 9(1), 31-52.

Clark, C. M. (1988). Asking the right questions about teacher preparation: Contributions of research on teacher thinking. Educational Researcher, 17(2), 5-12.

Clark, R. E. (1983). Reconsidering research on learning from media. Review of Educational Research, 53(4), 445-459. (Citation included in Kerr re relative effectiveness of media based education)

Clark, R. E. (1985). Confounding in educational computing research. Journal of Educational Computing Research, 1(2),137-148. (Citation included in Bitter re effectiveness of CBT)

Criswell, E. (1989). The design of computer-based instruction. New York: Macmillan.

Educational Technology Center, (1988). Making Sense of the Future: A position paper on the role of technology in Science, Mathematics and Computer Education. Cambridge, MA: Harvard Graduate School of Education.

Engelbart, D. C. (1988). The augmentation system framework. In S. Ambron \& K. Hooper, (Eds.). Interactive Multimedia: Visions of multimedia for developers, educators, and information providers. Redmond, WA: Microsoft Press.

Fielden, K. \& Steele, J. (1988). Hypercard and interactive video. In J. Steele \& J. G. Hedberg (Eds), EdTech'88: Designing for learning in industry and education. Belconnen, ACT: AJET Publications. pp.43-50. http: / / www.ascilite.org.au/aset-archives/confs/edtech88/fielden.html

Goldenberg, E. P. (1988). Mathematics, metaphors and human factors: Mathematical, technical and pedagogical challenges in the educational use of graphical representation of functions. Journal of Mathematical Behaviour, 7(2),135173.

Hativa, N. (1986). The microcomputer as a classroom audiovisual device: The concept, and prospects for adoption. Computer Education, 10(3), 359-367.

Hedberg, J. G. (1985). Designing interactive videodisc materials. Australian Journal of Educational Technology, 1(2), 24-31.

http:/ / www.ascilite.org.au/ajet/ajet1/hedberg2.html 
Hedberg, J. G. (1988a). Technology, Continuing Education and Open Learning or Technology 1 - Bureaucracy 0. In J. Steele, and J. G. Hedberg (Eds.), Designing for Learning in Industry and Education. Canberra: Australian Society for Educational Technology, pp90-94. http:/ / www.ascilite.org.au / aset-archives/ confs/edtech88/hedberg.html

Hedberg, J. G. (1988b). Designing Ask the Workers...: Teams and conceptualisation. In J. Steele (Ed.) Ask the Workers...: Evaluation. Sydney: Australian Caption Centre. pp17-35.

Hedberg, J. G. (1989a). CD-ROM: Expanding and shrinking resource-based learning. Australian Journal of Educational Technology, 5(1), 56-75. http: / / www.ascilite.org.au/ajet/ajet5/hedberg1.html

Hedberg, J.G. (1989b). The relationship between technology and Mathematics Education: Implications for Teacher Education. In Department of Employment, Education and Training, Discipline Review of Teacher Education in Mathematics and Science. Vol 3. Canberra: Australian Government Publishing Service, pp103137.

Hedberg, J. G. and McNamara, S. E. (1985). Matching Feedback and Cognitive Style in Visual CAI Tasks. Paper presented to the Annual Conference of the American Educational Research Association, Chicago, May.

Hedberg, J. G. and McNamara, S. E. (1989). The Human-Technology Interface: Designing for distance and open learning. Educational Media International, 26(2), 73-81.

Jackson, P. W. (1986). The practice of teaching. New York: Teachers' College Press.

Johnson, D. L., Maddux, C. D. \& O'Hair, M. M. (1988). Are we making progress? An interview with Judah L Schwartz of ETC. Computers in the Schools, 5(1 / 2), $5-22$.

Johnson, J. L. (1987). Microcomputers and secondary school mathematics: A new potential. Focus on Learning Problems in Mathematics, 9(2), 5-17.

Kaiser, B. (1988). Explorations with tessellating polygons. Arithmetic Teacher, 36(4), December, 19-24.

Kaput, J. J. (1986). Information technology and mathematics: Opening new representational windows. Journal of Mathematical Behaviour, 5(2), 187-207.

Kaput, J. J. (1987). Translational processes in mathematics education. In C. Janvier, (Ed.), Froblems of Representation in the Teaching and Learning of Mathematics. Hillsdale, NJ: Lawrence Erlbaum Associates. pp19-26.

Kemp, J. E. (1977). Instructional Design: A Plan for unit and course development. (2nd ed.) Belmont, CA: Fearon-Pitman.

Kerr, S. T. (1989). Teachers and technology: An appropriate model to link research with practice. Paper presented to the Annual Conference of the Association for Educational Communications and Technology, Dallas, Tx, February 1st to 5th.

Kreitzberg, C. B. \& Shneiderman, B. (1988). Restructuring knowledge for an electronic encyclopedia. Paper presented to the International Ergonomics Association, 10th Congress, Sydney, August 1st to 5th.

Kulik, J. A. \& Bangert-Downs, R. L. (1983-1984). Effectiveness of technology in pre college maths and science teaching. Journal of Educational Technology Systems, $12(2), 137-158$

Laurillard, D. (1987). Interactive Media: Working methods and practical applications. London: John Wiley.

Nation's future depends on reform of mathematics education. (1989, February 8th). Report on Education Research, pp. 3-4.

Office of Technology Assessment. (1988). Power on! New tools for teaching and learning. Washington, DC: US Government Printing Office. 
Papert, S. (1980). Mindstorms: Children, computers and powerful ideas. New York: Basic Books.

Pea, R. (1987). Cognitive Technologies for mathematics education. In A. H. Schoenfeld, (Ed.). Cognitive Science and Mathematics Education. Hillsdale, NJ: Lawrence Erlbaum Associates. pp89-122.

Pea, R., Soloway, E. \& Spohrer, J. C. (1987). The buggy path to the development of programming expertise. Focus on Learning Problems in Mathematics, 9(1), 5-30.

Percival, F. \& Ellington, H. (1988). A Handbook of Educational Technology. 2nd. ed. London: Kogan Page.

Reiser, R. A. (1987). Instructional technology: A history. In R. M. Gagne (Ed.), Educational technology: Foundations. Hillsdale, NJ: Lawrence Erlbaum. pp11-48.

Richey, R. (1986). The theoretical and conceptual bases of instructional design. New York: Kogan Page.

Roblyer, M. D., Castine, W. H. \& King, F. J. (1988). Assessing the impact of computer-based instruction: A review of recent research. Computers in the Schools, 5(3/4), 11-149.

Romiszowski,A. J. (1981). Designing Instructional Systems. London: Kogan Page.

Salomon, G. (1979). Interaction of media, cognition, and learning. San Francisco: Jossey-Bass.

Schoenfeld, A. H. (Ed.) (1987). Cognitive science and mathematics education. Hillsdale, NJ: Lawrence Erlbaum.

Schwartz, J. \& Yerushalmy, M. (1985). The geometric supposers. Pleasantville, NY: Sunburst Communications.

Scriven, M. \& Adams, K. (1988). Evaluation: The educational potentialities of videodisc. In J. Steele (Ed.) Ask the Workers...: Evaluation. Sydney: Australian Caption Centre. pp 51-97.

Shneiderman, B. (1982). Fighting for the user. Bulletin of the American Society for Information Science, 9(2), 27-29.

Shneiderman, B. (1987) Designing the User Interface: Strategies for Effective HumanComputer Interaction. Reading, MA: Addison Wesley.

Steele, J. \& Hedberg, J. G. (Eds.) (1988). Designing for Learning in Industry and Education. Belconnen, ACT: AJET Publications. http: / / www.ascilite.org.au/asetarchives / confs / edtech88/edtech88_contents.html

Steiglitz, E. L. \& Costa, C. H. (1988). A statewide teacher training program's impact on computer usage in the schools. Computers in the Schools, 5(1/2), 91-98.

Trollip, S. R. \& Alessi, S. M. (1988). Incorporating computers effectively in classrooms. Journal of Research on Computing in Education, 21(1), 70-81.

Author: John Hedberg was asked to prepare a paper on technology and learning Mathematics and Science for the recently completed Discipline Enquiry. This paper is a refocussing of the ideas to the general problems of selecting media for instructional tasks. He can be contacted at the Professional Development Centre, University of NSW, PO Box 1, Kensington NSW 2033.

Please cite as: Hedberg, J. G. (1989). Rethinking the selection of learning technologies. Australian Journal of Educational Technology, 5(2), 132-160. http: / / www.ascilite.org.au / ajet / ajet5/hedberg2.html 